\title{
A review of the pattern of AIDS defining, HIV associated neoplasms and premalignant lesions diagnosed from 2000-2011 at Kenyatta National Hospital, Kenya
}

\author{
Emily A. Rogena ${ }^{1 *}$, Kenneth O. Simbiri ${ }^{2}$, G. De Falco ${ }^{3}$, L. Leoncini ${ }^{4}$, Leona Ayers ${ }^{5}$ and J. Nyagol ${ }^{6}$
}

\begin{abstract}
Background: Sub-Sahara Africa hosts up to $71 \%$ of all HIV infected people in the world. With this high incidence of Human immunodeficiency virus ( HIV) comes the burden of co-morbidities such as malignant and premalignant lesions. Aids defining malignancies have been listed as Kaposi's sarcoma, Non-Hodgkin's lymphoma and invasive squamous cell carcinoma of the cervix. People with HIV/AIDS(PLWAS) have a higher risk of developing these neoplasms than the rest of the population. The pathogenesis of these neoplasms in people with HIV has been linked to immune suppression, persistent antigenic stimulation and cytokine dysregulation.

Current study analyzes and presents the patterns and trends in the presentation of HIV related malignancies in patients diagnosed through histopathology at Kenyatta National Hospital.
\end{abstract}

Aim: To describe the patterns of AIDS- defining and non-AIDS- defining malignancies and premalignant lesions 10 years pre- and post HAART period at Kenyatta National hospital, Kenya.

Methods and techniques: This was a hospital based descriptive cross sectional study. The Formalin fixed paraffin embedded (FFPE) blocks and histological reports of patients diagnosed between 2000 and 2011 were traced from archives. The patients' demographic data and clinical presentation was entered in an excel spreadsheet and the diagnosis and coding confirmed by a histopathologist. The data was then cleaned and analyzed using SSPS version 17.0 Ink.

Results: A total of 173 lesions were reviewed and analyzed. Of these $118(68 \%)$ were from females and 55 from males (32\%). The male to female ratio was 1:2. The age range was from two to 56 years with a median of 36 years. Kaposi sarcoma is the leading AIDS defining malignancy in Kenya while invasive squamous cell carcinoma of the conjunctiva is the leading non-AIDS defining malignancy. This is closely followed by invasive squamous cell carcinoma of the cervix and NHL.

Conclusion: Kaposi sarcoma is the leading AIDS associated neoplasm in Kenya. Physicians and caretakers managing and following up on HIV/AIDS patients should look out for Kaposi sarcoma as a form of IRIS following the institution of HAART in all HIV/AIDS patients. The incidence of invasive squamous cell carcinoma of the conjunctiva is increasing in PLWAS in Kenya. There is therefore a need to introduce early screening programs for squamous intraepithelial neoplasm of the conjunctiva in HIV/AIDS patients.

\footnotetext{
*Correspondence: rogena.emily@gmail.com

${ }^{1}$ Thematic Unit of Anatomic pathology, Department of Human pathology, College of Health Sciences, University of Nairobi (KNH CAMPUS), PO BOX 55050 00200, Nairobi, Kenya

Full list of author information is available at the end of the article
}

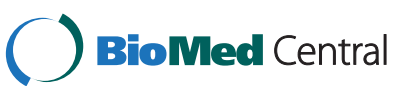

(c) 2015 Rogena et al. Open Access This article is distributed under the terms of the Creative Commons Attribution 4.0 International License (http://creativecommons.org/licenses/by/4.0/), which permits unrestricted use, distribution, and reproduction in any medium, provided you give appropriate credit to the original author(s) and the source, provide a link to the Creative Commons license, and indicate if changes were made. The Creative Commons Public Domain Dedication waiver (http://creativecommons.org/publicdomain/zero/1.0/) applies to the data made available in this article, unless otherwise stated. 


\section{Introduction and background}

Sub-Saharan Africa hosts up to $71 \%$ of all adults and children living with HIV, $70 \%$ of adults and children newly infected, and $75 \%$ of adults and children dying from AIDS [1]. In Kenya 1.6million people were living with HIV, with a prevalence rate of $6.1 \%$ in adults $15-$ 49 years of age, and death due to AIDS of 57,000 in 2012 [1]. With this high incidence and prevalence of HIV comes the burden of co-morbidities such as malignant and premalignant lesions [2]. AIDS defining malignancies have been listed as Kaposi sarcoma, NonHodgkin's lymphoma and invasive squamous cell carcinoma of the cervix $[3,4]$. People with HIV/AIDS have a higher risk of developing these neoplasms than the normal population [3]. The pathogenic mechanisms of these neoplasms are still not well understood although several authors suggest immune suppression, persistent antigenic stimulation, and elevated pro-inflammatory cytokines and other viruses as cofactors. [2]. Some of the cytokines that have been associated with these cancers include vascular endothelial growth fact VEGF, Kaposi's sarcoma growth factor KSGF, IL-6, and HIV Tat protein and IFgamma and alpha [5, 6]. These cytokines and factors influence the cell cycle and hence proliferation via several mechanisms that will not be discussed in this article. Although the sub-Saharan Africa leads in the incidence of HIV/AIDS, data on trends of AIDS associated malignancies in African countries is scanty [7-9]. This is partly attributed to the lack of well-established cancer registries [7-11], as is the case in Kenya. Most of the data in literature emanates from Uganda, possibly due to the presence of an active Kampala cancer registry which has been in existence since 1954 [12]. Literature from the developed countries show that following the introduction of HAART, the incidence of KS was significantly reduced amongst HIV/AIDS patients [2]. In addition the incidence of other neoplasms that are not AIDS defining have increased in these patients [2]. There has been an increase in the incidence of other neoplasms also referred to as non-AIDS defining neoplasm such as Hodgkin's lymphoma, myeloma, hepatocellular carcinoma and gastric adenocarcinoma [2]. It is against this background that we set out to review the trend of HIV related malignancies seen at our department of Pathology between 2000 to 2011. In this study we describe the patterns of AIDS- defining and non-AIDS- defining malignancies and premalignant lesions 11 years pre- and post HAART period at Kenyatta National hospital Kenya (Table 1).

\section{Methods and techniques}

Having obtained approval from the $\mathrm{KNH} / \mathrm{UON}$ ethics and research committee. The data clerk at the AIDS and Cancer Specimen Resource-Kenya (ACSR K) retrieved all the reports indicated to be HIV positive on the histological request forms between 2000 and 2011. This was done by checking for clinical information on the form indicating p24 marker positive (p24 is a marker of HIV antigenicity in serum), retroviral disease, if patient was on ARV or HAART treatment, or patient on followup at the comprehensive care clinic (CCC). Using the histological reports, blocks for the respective cases were then retrieved from the routine block storage and archived. 4 The criteria for inclusion as HIV positive case included information from the clinician in the patient's histological request form indicating follow up at the CCC, HAART treatment, ARV treatment, immunosuppression, p24 marker reactive, retrovirus disease, and HIV positive.

The patients' demographic and clinical data from the histological request form and partly from the hospital medical records were entered into Microsoft Excel 2010. Ink spreadsheet. The data was cleaned and analyzed using SPSS statistics 17.0 Ink.

\section{Results}

A total of 173 lesions were reviewed and analyzed by the study histopathologists (Ndungu, JR, Rogena, EA). Of these 118 (68\%) were females and 55 males ( $32 \%)$. The male to female ratio was 1:2. The age range was from 2 to 56 years with a median of 36 years (Fig. 1). Between the year 2000 and 2003, the main neoplasm reported was Kaposi's sarcoma and squamous cell carcinoma. Starting from 2003, other neoplasms such as High grade Non-Hodgkin's lymphoma and gastric adenocarcinoma began to emerge. Kaposi's sarcoma represents the largest number of cases at $48 \%$ followed by squamous cell carcinoma of the conjunctiva and cervix/vulva at $12.5 \%$ and $5.6 \%$ respectively. Aggressive Non-Hodgkin's lymphoma account for $4.6 \%$; of these lymphomas and Burkitt lymphoma make up $0.6 \%$. The premalignant lesion, carcinoma-in-situ (CIS),is seen both in the cervix and the conjunctiva. However, squamous cell carcinoma is more prevalent in the conjunctiva (Fig. 2). In our sample the aggressive non-Hodgkin's lymphomas are found in the less common sites such as the appendix and the skin. The only Burkitt lymphoma reported was in an adult, involving the appendix. Kaposi's sarcoma is also seen frequently in the appendix and the oropharynx. Of interest is the lack of ano-rectal carcinoma in this series (Figs. 3 and 4).

\section{Discussion}

The male to female ratio of 1:2 reported to have AIDS Related malignancies is in keeping with the higher incidence of HIV infection in the female population in Kenya as shown by the National HIV indicators for Kenya 2010 (National HIV Indicators for Kenya: 2010 National AIDS Control Council and the National AIDS 
Table 1 Distribution of the types of neoplasms and premalignant lesions by site

\begin{tabular}{|c|c|c|c|c|c|c|c|c|c|c|c|}
\hline $\begin{array}{l}\text { SITE OF } \\
\text { BIOPSY }\end{array}$ & $\mathrm{HL}$ & $\begin{array}{l}\text { Kaposi } \\
\text { sarcoma }\end{array}$ & $\begin{array}{l}\text { Squamous } \\
\text { cell } \\
\text { carcinoma }\end{array}$ & Adenocarcinoma & $\begin{array}{l}\text { Burkitt } \\
\text { lymphoma }\end{array}$ & $\begin{array}{l}\text { Aggressive } \\
\mathrm{NHL}\end{array}$ & $\begin{array}{l}\text { Carcinoma-in- } \\
\text { situ/severe } \\
\text { dysplasia }\end{array}$ & $\begin{array}{l}\text { Ductal } \\
\text { carcinoma }\end{array}$ & $\begin{array}{l}\text { Hepatocellular } \\
\text { carcinoma }\end{array}$ & $\begin{array}{l}\text { High } \\
\text { grade } \\
\text { sarcoma }\end{array}$ & Total \\
\hline Skin & & 35 & 1 & 0 & 0 & 2 & 0 & 0 & 0 & 0 & 38 \\
\hline Cervix/Vulva & 0 & 0 & 10 & 0 & 0 & 0 & 20 & 0 & 0 & 0 & 30 \\
\hline $\begin{array}{l}\text { Orbit/Eye/ } \\
\text { Conjunctiva }\end{array}$ & 0 & 3 & 22 & 0 & 0 & 0 & 8 & 0 & 0 & 0 & 33 \\
\hline Appendix & 1 & 15 & 1 & 0 & 1 & 5 & 0 & 0 & 0 & 1 & 24 \\
\hline $\begin{array}{l}\text { Stomach/ } \\
\text { Gastric }\end{array}$ & 0 & 0 & 1 & 1 & 0 & 0 & 0 & 0 & 0 & 0 & 2 \\
\hline Uterus & 0 & 0 & 1 & 0 & 0 & 0 & 5 & 0 & 0 & 0 & 6 \\
\hline Breast & 0 & 0 & 0 & 0 & 0 & 0 & 0 & 1 & 0 & 0 & 1 \\
\hline $\begin{array}{l}\text { Bone/Soft } \\
\text { tissue }\end{array}$ & 0 & 0 & 2 & 1 & 0 & 0 & 0 & 0 & 0 & 0 & 3 \\
\hline $\begin{array}{l}\text { Tongue/Oral } \\
\text { cavity/gingival }\end{array}$ & 0 & 14 & 5 & 0 & 0 & 0 & 0 & 0 & 0 & 0 & 19 \\
\hline $\begin{array}{l}\text { Oropharynx/ } \\
\text { palate/PNS } \\
\text { nose }\end{array}$ & 0 & 15 & 0 & 0 & 0 & 0 & 0 & 0 & 0 & 0 & 15 \\
\hline Liver & 0 & 0 & 0 & 0 & 0 & 0 & 0 & 0 & 1 & 0 & 1 \\
\hline Penis & 0 & 0 & 1 & 0 & 0 & 0 & 0 & 0 & 0 & 0 & 1 \\
\hline $\begin{array}{l}\text { Total (4 sites } \\
\text { were not } \\
\text { recorded) }\end{array}$ & 1 & 82 & 173 & 173 & 173 & 173 & 173 & 173 & 173 & 173 & 173 \\
\hline
\end{tabular}

and STD Control Program). The female gender is at a higher risk of acquiring HIV infection due to many factors such as the anatomy and the immunity of the reproductive system and socio-economic factors [1, 11]. Over the years Kaposi sarcoma, squamous cell carcinoma of the uterine cervix and High Grade Non-Hodgkin's

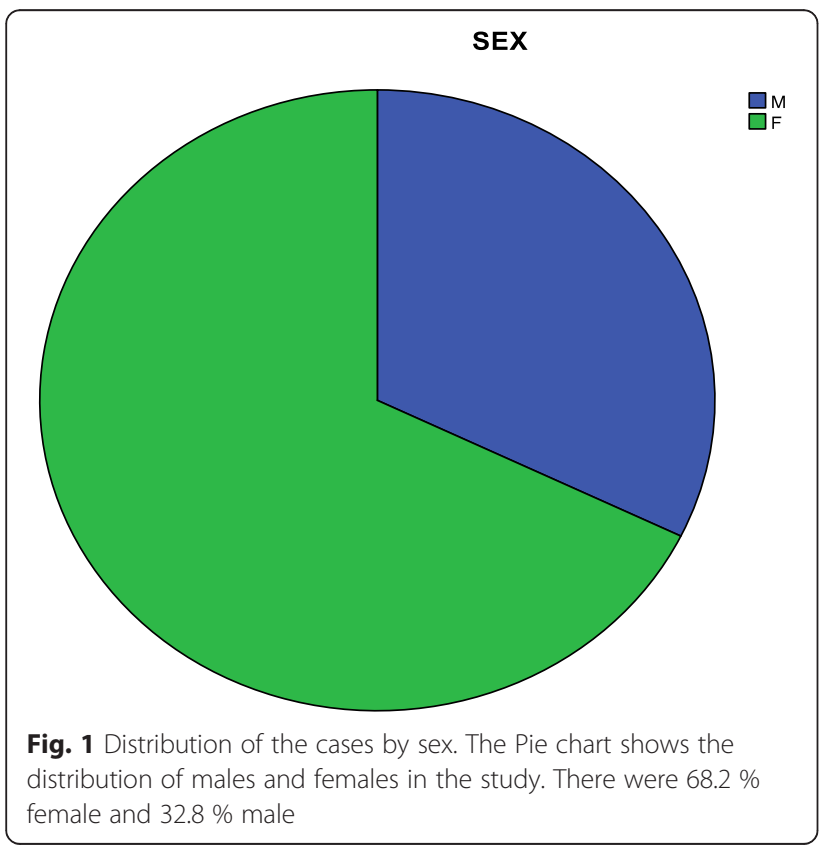

lymphomas have been listed as AIDS defining malignancies. The AIDS defining malignancies are neoplasms that consistently correlate with the presence of AIDS in HIV infected persons. In a pilot study by Korir et al. in Kenya, the authors observed that of 171 cases, 118 had tumors associated with HIV, including Kaposi's sarcoma, cervical cancer, non- Hodgkin's lymphoma, Hodgkin's disease, and conjunctival carcinoma [11]. The non-AIDS defining malignancies appear to occur at much younger age in HIV infected persons compared to those that are HIV negative, the neoplasms show atypical features, and a higher grade and stage at the time of diagnosis [12].

The data in this study reveals a progressive increase in the number and variety of malignancies and premalignant lesions diagnosed since the introduction of HAART in 2003. The trend is such that Kaposi's sarcoma and squamous cell carcinoma of the cervix and vulva predominated between 2000 and 2003, the pre HAART period in Kenya. Kaposi's sarcoma is still leading, but incidence of squamous cell carcinoma of the conjunctiva is surpassing that of the cervix and vulva. Later in 2003, majority of HIV patients started receiving ARV from MEDS (Mission for essential drug suppliers- a catholic church NGO). Following this, in the same year, the Kenya government announced the inception of HAART treatment through public hospitals which were implemented through funding by GLOBAL and PEPFAR funds in 2004 [15]. Over the period of eight years, up to 


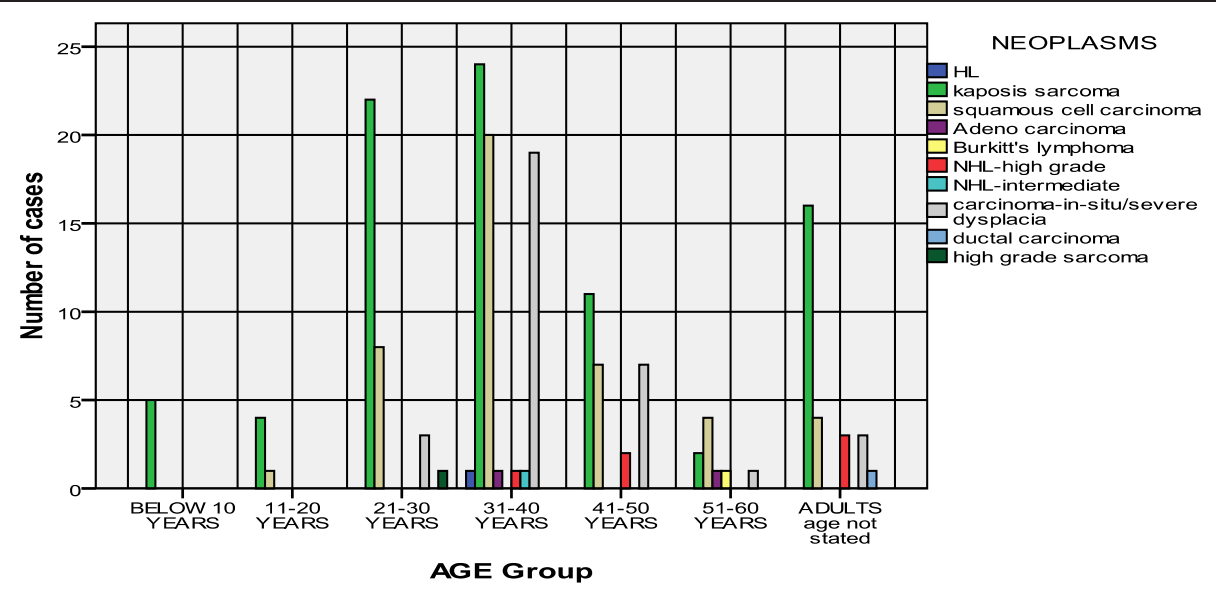

Fig. 2 The distribution of types of Lesions by age. The figure shows the distribution of cancers by age of diagnosis in HIV-1 cases in Kenyatta National Hospital between 2001 and 2011

1million Kenyans have been put on HAART. One expects an increase in the survival of people living with HIV/AIDS. The developed countries over the years have recorded a significant decrease in the incidence of AIDS related malignancies since the introduction of HAART in those settings [16]. In Kenya, the trend appears to demonstrate a relative increase in the number of cases and the variety of AIDS related malignancies. This could be accounted for by the survival rate of these patients as the HAART programs become widespread. Another factor that may contribute to the high incidence is the endemicity of KSHV (HHV8) in East Africa. In this study we did not actively review the information on the correlation of HAART use and the neoplasm. Nor did we correlate the KSHV marker, LANA 1 marker and the presence of Kaposi's sarcoma as objectives of the study.

Reports from Kampala, Uganda show that HIV related Kaposi's sarcoma affects mainly the younger and middle age groups, and the median age in 1990s being 32.0 years and 27.1 years for men and women respectively. This distribution is similar to the median age of AIDS cases recorded for the country in 1996 of 34 years and 30 years in men and women respectively [12]. KS can involve any site in HIV infected persons, including bone marrow, pancreas, gastrointestinal tract (GIT), lungs, liver, heart, and testis [17]. The oral cavity, palate and larynx are other common sites. Of the 82 cases of Kaposi's sarcoma reported in this study $(42.7 \%)$ showed involvement of

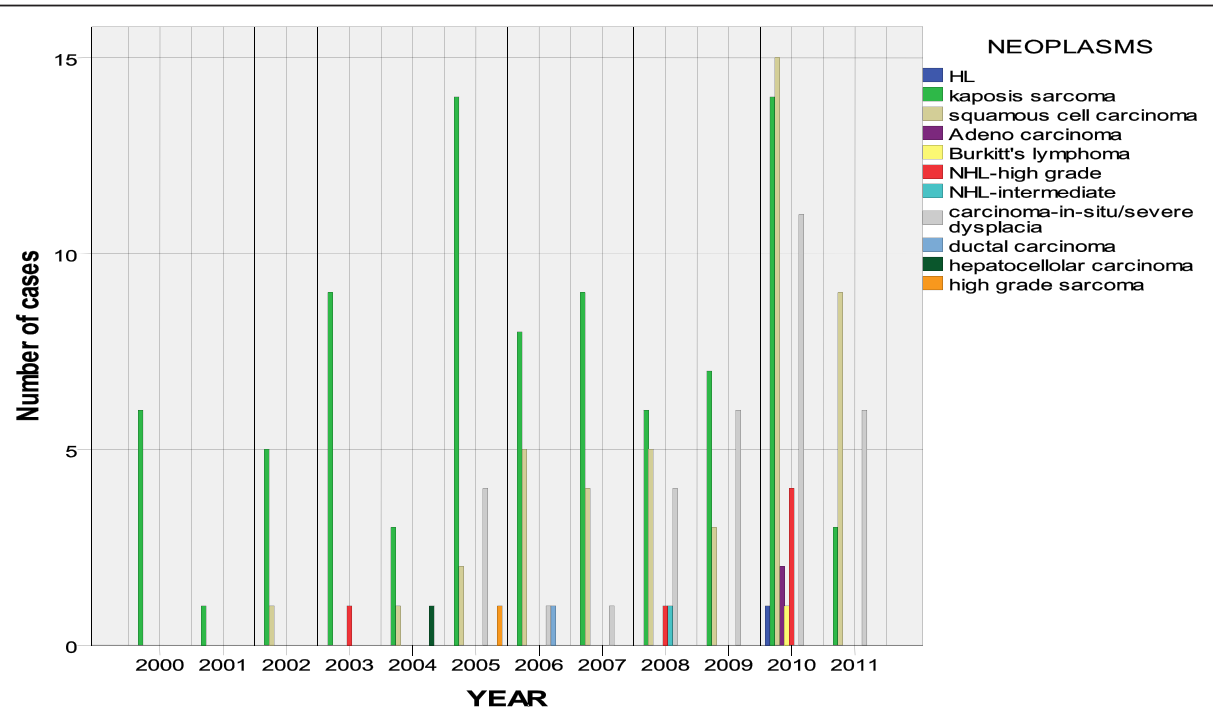

Fig. 3 The distribution of neoplasms Reported between 2000 and 2011. The figure shows the cancers identified in Kenyatta National Hospital in 2001-2011 using patient charts and FFPE 


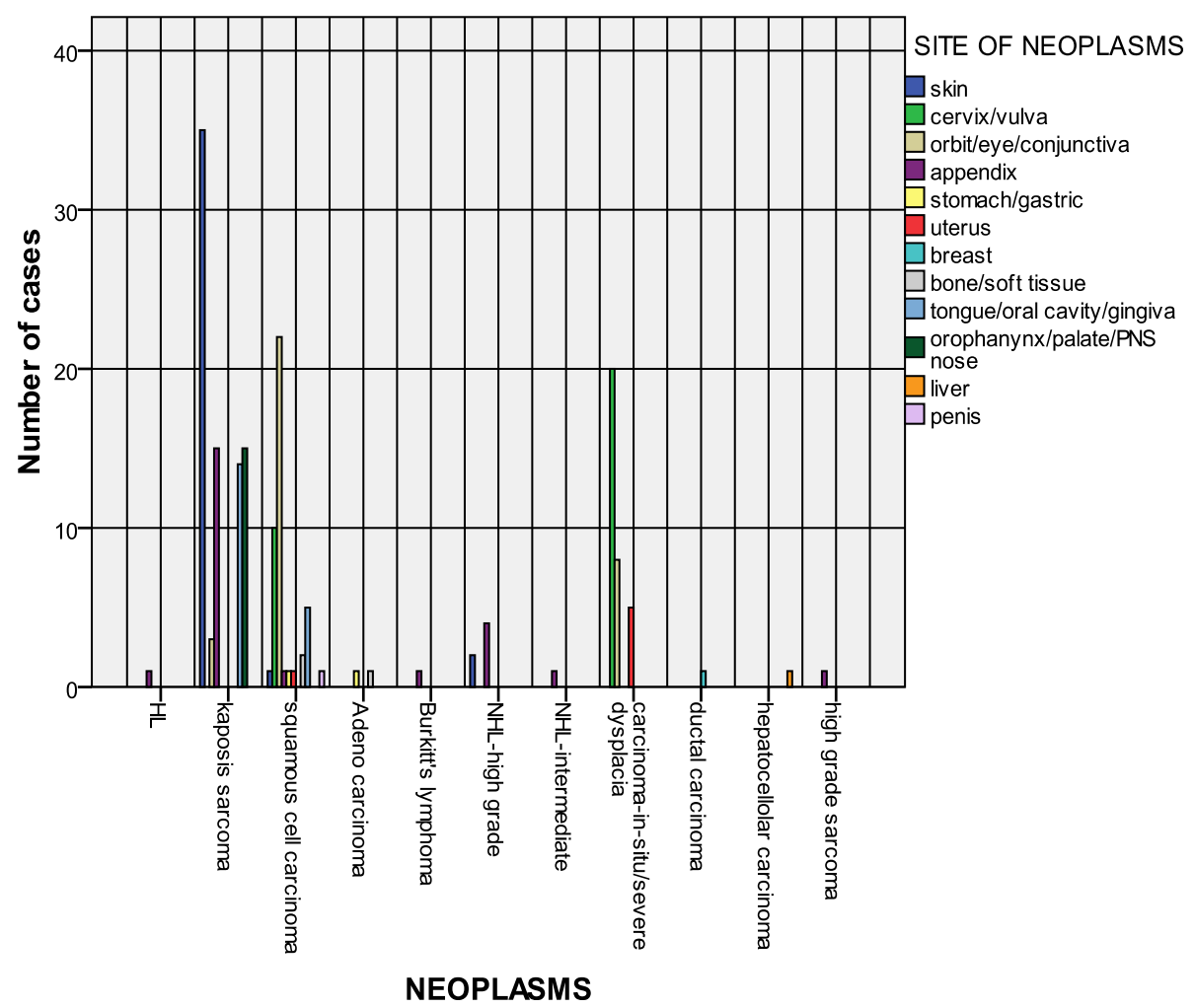

Fig. 4 The distribution of neoplasms by site. The figure shows specific types of neoplasms detected at Kenyatta National Hospital with respect to site

KS in the skin, the appendix and oro/nasopharynx/palate represented $15 \%$ each, and the conjunctiva and tongue/ oral mucosa was at $3.7 \%$ and $17.1 \%$ respectively. Kaposi's Sarcoma associated with HIV is said to be more aggressive and has been shown to occur at these unusual sites [12]. This observation has led to the proposal that HIV-1 encoded proteins such as Tat protein may induce some cytokines that work synergistically with products of HHV8 [16, 18, 19]. Tat interacts with RB2/P130 tumor suppressor gene among other pathways [20]. KS may flare up upon introduction of HAART in some cases. This is thought to be due to Immune reconstitution syndrome, a reaction to some of the infections seen in HIV [21]. Due to the scanty nature of the clinical information accompanying histological specimens to the laboratory, one would not easily elucidate this syndrome using laboratory data. Recent studies from Kenya, Uganda and South Africa show that HAART is effective in reducing the standardized incidence of KS [22].

Invasive squamous cell carcinoma of the cervix is classified as one of AIDS defining malignancies. The occurrence of this neoplasm in HIV represents a progression to AIDS. The neoplasm is directly linked to HPV, a virus that has been shown to transform squamous cells through the E6 and E7 proteins. These proteins act via the cyclin dependent kinases E/CDK2 to phosphorylate and inactivate RB gene. Proposals have been put forth suggesting that HIV may upregulate E6 and E7 through Tat [23]. Whereas the pathogenesis of squamous cell carcinoma of the conjunctiva and that of the cervix is similar, the study shows that invasive squamous cell carcinoma of the conjunctiva has surpassed that of the uterine cervix. On the other hand CIS is more prevalent in the uterine cervix than in the conjunctiva. This reversed trend could be as result of the cervical screening programs in Kenya, targeting all women. However, there is no such program targeting the conjunctiva in PLWAs in Kenya. A review of HIV related cancers in Uganda revealed a dramatic increase in invasive squamous cell carcinoma of the conjunctiva from four cases reported between 1960 to 1971 and 66 cases reported between 1994 and 1997 [12]. Similarly, Ateenyi from Uganda demonstrated similar positive correlation between squamous cell carcinoma of the conjunctiva and HIV in 1995 [24]. Although cancer of the cervix is classified as AIDS defining, Uganda series do not show a significant risk between HIV positive and HIV negative women. However, the Ugandan reports reveal a significant link between CIS and HIV infection [16]. Nonetheless, lesions diagnosed through screening programs have to be 
interpreted with caution taking into consideration the biases introduced by screening programs that lead to the diagnosis of these premalignant lesions such as CIS.

In general aggressive $\mathrm{B}$ cell lymphomas are one of the nightmares in management of HIV/AIDS. These neoplasms are usually non-responsive to routine protocols. Diffuse large B cell lymphomas form the largest percentage followed by Burkitt lymphoma. Non Hodgkin's lymphoma put together accounted for $4.6 \%$ of all the neoplasms and premalignant lesions in this study. In the United States, the relative risk of NHL in subjects with AIDS is 100 or more and much higher than the relative risk in an African series reporting that shows Rwanda leads at 13 [95\% confidence interval (CI), 2.2-44.4] [25] and South Africa at 4.8 (95 \% CI, 1.5-14.8) [26]. The risk of developing lymphoma steadily increases with duration of HIV infection and advancing immunosuppression. Prospects for increased survival are enhanced by HAART; however, long-term survivors of HIV infection may remain at increased risk for NHL [27]. The slow roll out of HAART use may partly account for death of HIV/ AIDS patients earlier in this setting prior to the diagnosis of lymphomas hence the low reported incidence in this study.

Burkitt lymphoma in sub-Saharan Africa is mainly a childhood disease accounting for up to $82 \%$ of all pediatric and adolescent lymphomas in the region [28]. HIV related BL however occurs mainly in adults as shown in this study and presents at unusual sites. All the cases of Burkitt lymphomas in the HIV/AIDS patients were reported between the ages of 51 to 60 years. The numbers given in this study may be an underestimation since the main diagnostic method for Burkitt lymphoma has been Fine needle aspiration Cytology (FNAC). Therefore histological records would understate the incidence.

Recent data reported from several hospitals in East Africa reveal that Hodgkin's Lymphoma is a disease of children and adolescents [28], the only case of Hodgkin's lymphoma in this review was reported between the age of 31 to 40 years. The disease has been reported to be on the increase in HIV/AIDS [16]. There appears to be a linkage between EBV and HIV in the pathogenesis of lymphomas, a fact that calls for further research. Nearly all HLs are associated with EBV [23]. The EBV related proteins EBNA 1, EBNA 2, EBNA-LP, EBNA 3A and EBNA-3C and LMP differentially drive the cells through notch pathway, cell cycle check point (G2/M) and by activation of NF-kB [29]. We would like to point out that a number of the cases diagnosed in the period may not have been retrieved due to challenges in record keeping.

Although Burkitt lymphoma is one of the well reported high grade lymphomas seen in HIV/AIDS, the cases reported in this study were very few. Of note is that during the period under review, the main diagnostic method for Burkitt lymphoma was largely through FNAC, and may account for the low incidence of archived tissue of BL in this series.

\section{Conclusion}

Kaposi sarcoma is the leading AIDS associated neoplasm in Kenya. The incidence of invasive squamous cell carcinoma of the conjunctiva is increasing in PLWAS in Kenya. There is therefore a need to introduce early screening programs for squamous intraepithelial neoplasm of the conjunctiva in HIV/AIDS patients.

\section{Competing interests}

The authors declare that they have no competing interests.

\section{Authors' contributions}

EAR designed the study, reviewed the lesions, interpreted the data, and drafted the manuscript; KOS designed the study, interpreted data, drafted the manuscript, and edited the manuscript; LL designed the study, interpreted data, and drafted the manuscript; LA designed the study, interpreted data, and drafted the manuscript; JN designed the study, reviewed the lesions, interpreted the data, and drafted the manuscript; and GF designed the study, interpreted data, and drafted the manuscript. All authors have read and approved the final manuscript.

\section{Acknowledgments}

We sincerely acknowledge the NIH and OSU (of Mid region ACSR) for funding the ACSRK, a tissue archive project from where this data has been obtained. The AIDS and Cancer Specimen Resource (ACSR) of the National Cancer Institute (NCI) AIDS Malignancy Program provides HIV/AIDS-related malignant tissues and data to funded/approved cancer researchers to promote a global understanding of the relationships between HIV infection and certain cancers. The ACSR Kenya is situated at the department of Human Pathology, University if Nairobi, and was started as an affiliate of OSU in 2009 and is guided by NCl Best Practices for Bio-specimen Resources. The site has a principal task of collecting, enhancing, storing, and distributing HIV related, quality assured human tumor tissue with associated clinical, pathological, visual and demographic data to approved investigators. ${ }^{8}$ We hope that with improved quality of the specimens and availability of data, there will be an increase in translational research in area of HIV/AIDSrelated malignancies from developing countries such as Kenya. We also envisage that the research and publications will contribute to control and management of HIV/AIDS and support the area of targeted therapies in cancer in general.

\section{Author details}

${ }^{1}$ Thematic Unit of Anatomic pathology, Department of Human pathology, College of Health Sciences, University of Nairobi (KNH CAMPUS), PO BOX 55050 00200, Nairobi, Kenya. ${ }^{2}$ Department of Microbiology and Immunology, SUNY Upstate Medical University, New York, USA. ${ }^{3}$ School of Biological and Chemical Sciences Queen Mary University of London, London, UK.

${ }^{4}$ Department of Medical Biotechnologies, University of Siena, via Delle Scotte, 6, Siena 53100, Italy. ${ }^{5}$ Mid region AIDS Cancer specimen resource, (NCI), Ohio State University, 2046, Innovation Centre 2001 Polaris Parkway, Columbus, Ohio 43240, USA. ${ }^{6}$ Thematic Unit of Immunology Department of Human pathology, College of Health Sciences, University of Nairobi (KNH CAMPUS), PO BOX 19676 00202, Nairobi, Kenya.

Received: 24 September 2014 Accepted: 14 July 2015

Published online: 24 August 2015

\section{References}

1. Global Report: UNAIDS report on the global AIDS epidemic. 2012.

2. Spanoa JP, Atlan D, Breau JL, Farge D. AIDS and non-AIDS-related malignancies: a new vexing challenge in HIV-positive patients Part I: Kaposi's sarcoma, non-Hodgkin's lymphoma, and Hodgkin's lymphoma. Eur J Int Med. 2002;13:170-9. 
3. Mbulaiteye SM, Parkin DM, Rabkin CS. Epidemiology of AIDS-related malignancies an international perspective. Hematol Oncol Clin North Am. 2003;17(3):673-96. v.

4. Parkin DM, Bray F, Ferlay J, Jemal A. Cancer in Africa 2012. Cancer epidemiology, biomarkers \& prevention: a publication of the American Association for Cancer Research, cosponsored by the American Society of Preventive Oncology. 2014

5. Simbiri KO, Jha HC, Dzeng RD, Massaro-Giordano G, Robertson ES. Cytokine and Chemokine Expression Profiles in HIV-1 Infected Patients with Ocular Surface Squamous Neoplasia from Botswana. Cancer Clin Oncol. 2012;1(2):10-24.

6. Simbiri KO, Robertson ES. Characterization of the OSSN Microbiome in HIV-1 Infected Patients. Cancer Clin Oncol. 2012;1(1):88-101.

7. Thomas JO. Acquired immunodeficiency syndrome-associated cancers in Sub- Saharan Africa. Semin Oncol. 2001;28(2):198-206.

8. Buonaguro FM, Gueye SN, Wabinga HR, Ngoma TA, Vermorken JB, Mbulaiteye SM. Clinical oncology in resource-limited settings. Infect Agent cancer. 2013;8(1):39.

9. Kostelecky B, Trimble EL, Bhatia K. Learning lessons from cancer centers in low- and middle-income countries. Infect Agent cancer. 2013;8(1):44.

10. Dal Maso L, Serraino D, Franceschi S. Epidemiology of AIDS-related tumours in developed and developing countries. Eur J Cancer. 2001;37(10):1188-201.

11. Korir A, Mauti N, Moats P, Gurka MJ, Mutuma G, Metheny C, et al. Developing clinical strength-of-evidence approach to define HIV-associated malignancies for cancer registration in Kenya. PLoS ONE. 2014;9(1):e85881.

12. Parkin DM, Wabinga $H$, Nambooze S, Wabwire-Mangen F. AIDS-related cancers in Africa: maturation of the epidemic in Uganda. AIDS. 1999;13(18):2563-70.

13. National HIV Indicators for Kenya. National AIDS Control Council and the National AIDS and STD Control Program. 2010.

14. Pantanowitz L. Overview of non-AIDS-defining malignancies in HIV infection. Literature review current through: 20.3: gen 2012. This topic last updated: lug 19, 2011, http/29th February 2012

15. WWW.globalhealth.org/03rd october 2011. FBO contributing to rapid scale up of ART, The story of MEDS Kenya-2000-2011GLOBAL HEALTH COUNCIL.

16. Mbulaiteye SM, Parkin MD, Rabkin CS. Epidemiology of AIDS-related malignancies -An international perspective. Hematol Oncol Clin N Am. 2003;17:673-96.

17. Joachim HL, Adsay V, Giancotti FR, Dorsett B, Melamed J. Kaposi's sarcoma of internal organs. A multiparameter study of 86 cases. Cancer. 1995;75:1376-85

18. Albini A, Barillari G, Benelli R, Gallo RC, Ensoli B. Angiogenic properties of humanimmunodeficiency virus type 1 Tat protein. Proc Natl Acad Sci U S A. 1995;92(11):4838-42.

19. Prakash O, Tang ZY, He YE, Ali MS, Coleman R, Gill J, et al. Human Kaposi's sarcoma cell-mediated tumorigenesis in human immunodeficiency type 1 tat expressing transgenic mice. J Natl Cancer Inst. 2000;92(9):721-8.

20. Lazzi S, Bellan C, De Falco G, Cinti C, Ferrari F, Nyongo A, et al. Expression of RB2/p130 tumor-suppressor gene in AIDS-related non-Hodgkin's lymphomas: implications for disease pathogenesis. Hum Pathol. 2002;33(7):723-31.

21. Leidner R, Aboulafia D. Flare of AIDS associated KS following HAART: a manifestation of IRIS. In: program and abstract of the 8th international conference on malignancies in AIDS and other Immunodeficiencies; 2004; Bethesda Md.

22. Semeere AS, Busakhala N, Martin JN. Impact of Antiretroviral Therapy on the Incidence of Kaposi's Sarcoma in Resource-rich and Resource-limited Settings. Curr Opin Oncol. 2012;24(5):522-30. doi:10.1097/ CCO.0b013e328355e14b. accessed 21st June 2013 ). 10.

23. Bellan C, De Falco G, Lazzi S, Leoncini L. Pathologic aspects of AIDS malignancies. Oncogene. 2003;22:6639-45.

24. Ateenyi-Agaba C. Conjunctival squamous-cell carcinoma associated with HIV infection in Kampala, Uganda. Lancet. 1995;345:695-6.

25. Newton R, Grulich A, Beral V, Sindikubwabo B, Ngilimana PJ. Cancer and HIV infection in Rwanda [letter]. Lancet. 1995;345:1378-9.

26. Sitas F, Bezwoda WR, Levin V, Ruff P, Kew MC, Hale MJ, et al. Association between human immunodeficiency virus type 1 infection and cancer in the black population of Johannesburg and Soweto, South Africa. Br J Cancer. 1997;75:1704-7.

27. Otieno MW, Banura C, Katongole-Mbidde E, Johnson JL, Ghannoum M, Dowlati A, et al. Therapeutic challenges of AIDS related non-Hodgkin's lymphoma in the United States and East Africa. J Natl Cancer Inst. 2002;94(10):718-32

28. Naresh KN, Raphael M, Ayers L, Hurwitz N, Calbi V, Rogena E, et al. Lymphomas in sub Saharan Africa-what can we learn and how can we help in improving diagnosis, managing patients and fostering translational research? Br J Haematol. 2011;154:696-703.

29. Ambinder RF. Epstein-Barr virus associated lymphoproliferations in the AIDS setting. Eur J Cancer. 2001;37(10):1209-16.

\section{Submit your next manuscript to BioMed Central and take full advantage of:}

- Convenient online submission

- Thorough peer review

- No space constraints or color figure charges

- Immediate publication on acceptance

- Inclusion in PubMed, CAS, Scopus and Google Scholar

- Research which is freely available for redistribution 